\title{
Mentoring Needs and Expectations of Generation-Y Human Resources Practitioners: Preparing the Next Wave of Strategic Business Partners
}

\author{
Carolin Rekar Munro \\ Faculty of Management, Royal Roads University \\ 2005 Sooke Road, Victoria, B.C. V9B 2Y5, Canada \\ Tel: 1-250-391-2600Ｅ-mail: carolin.rekarmunro@royalroads.ca
}

\begin{abstract}
As organizations prepare for the arrival of Generation-Y HR practitioners as the next generation of strategic business partners in our $21^{\text {st }}$ century workplaces, questions ignite about Generation-Y's values and aspirations, and how we can engage them in our workplaces. At the forefront of organizational initiatives is mentorship which has resurged as a leading employee development tool. The purpose of this paper is to: examine the benefits of mentorship and the challenges and opportunities of Generation-Y engagement in the workplace; present results from a study on mentoring needs and expectations of Generation-Y HR practitioners; and; present a mentorship model built on collaboration and an action research framework. Surveys, focus groups, and one-on-one interviews with 452 participants generated robust data on the needs and expectations of Generation- $Y$ in the formative years of their careers. Results are presented in the following thematic areas: competency profile of effective mentors, framework for mentor-protégé working relationships, anticipated outcomes of mentoring, approaches to learning and development, e-mentoring, and protégés' contributions to mentoring relationships. Findings reveal that mentoring is vital to development of the competencies for senior HR accountabilities and for understanding how HR fulfils strategic mandate. To achieve this mandate a five-phase mentoring model is proposed with an emphasis on sparking synergy between Generation-Y's personal values and organizational objectives. The need for mentorship programs with a strategic orientation is timely as HR continues to assert its leadership presence at the boardroom table and prepares the next generation of HR practitioners under whose leadership global communities will thrive.
\end{abstract}

Keywords: Mentoring, Generation-y, Leadership development, Human resources, Succession planning, Employee engagement 


\section{Introduction}

Entering the workforce by storm is a new wave of Human Resources practitioners, Generation Y (Gen Y), who bring distinct values, assumptions, and behaviours; and foster widespread organizational concern regarding how to engage them in the workplace. With the arrival of Gen Y, organizations are re-strategizing how to attract and retain star HR performers as their competitive advantage in a steadily dwindling labour market. At the forefront is mentoring which has resurged as a leading employee development tool, especially for leadership (Noe et al., 2002). Regenerated interest in mentoring stems from awareness that competitive advantage is achieved through employee development (Kanter, 1999) at a time when mass retirement of Baby Boomers is contributing to depletion of organizational knowledge (Stanek, 2001).

As provisions for employee development are made, questions are ignited about mentoring needs and expectations of Gen-Y HR practitioners; and how they can be incorporated into formalized mentorship programs. Rationale for doing so originates from a study on the experiences of Gen-Y HR practitioners as they transition from academia to the workplace. Mentoring was identified by $85 \%$ of new recruits as the cornerstone of successful workplace transitioning, yet only 32\% were satisfied with mentoring received; 38\% would have preferred better support systems; and 21\% received no mentoring (Rekar Munro, 2007).

Mentorship not only launches HR careers, but carries strategic implications for the profession. Carving out a credible and enduring role as strategic business partner at the boardroom table hinges on commitment and capacity to mentor the next generation of HR practitioners; ultimately, to assume principal accountability for managing human capital. Mentorship fuels astute business decisions; empowers engagement in strategic planning, implementation, and management; and develops skills to lead in volatile organizational landscapes. New recruits also learn tools of the mentorship trade so as future leaders they champion mentoring initiatives for subsequent generations of HR practitioners and for professional disciplines throughout their organizations.

The purpose of this paper is to: 1) contribute knowledge of the benefits of mentoring, and challenges and opportunities of Gen Y engagement in the workplace; 2) present results from a study on mentoring needs and expectations of Gen-Y HR practitioners; 3) discuss implications for practice, and; 4) present a conceptual model of mentoring to engage Gen Y at a fundamental level and transform engagement into high performance.

It is anticipated this paper will interest new and experienced HR practitioners. For those entering the profession, it might be the foundation for developing their own mentorship programs and test driving them in their organizations. For seasoned practitioners it hopefully will engage discussion about the future of mentorship, and inspire them to refine their own mentoring practices to support shifting attitudes, expectations, and behaviours of the next generation of HR leaders. For both, interest might spark ongoing inquiry into effective approaches for mentoring so the bar continues to be raised on the standard for excellence. As new benchmark standards take root, mentoring has potential to become the quintessential ingredient in professional development for HR practitioners, enabling the profession to fulfil 
its mandate of building organizational prosperity through management of human capital; ultimately, sealing the organization's competitive advantage.

\section{Merits of Formal Mentorship}

Studies show 70 - 90\% of workplace learning occurs through mentoring and informal on-the-job training (Pfeffer \& Sutton, 2000; Tannenbaum,1997), and at least one third of organizations with a minimum of 500 employees have launched formal mentoring (Kim, 2007; Nemanick, 2000).

Mentoring accelerates career progression, acclimatizes new recruits to organizational culture and values; and is recognized as an unrivalled approach for transferring organizational wisdom, skills, and abilities from seasoned practitioners to new recruits (Rosser, 2005; Peterson, 2002; Linehan \& Walsh, 1999). Resultant is more effective learning that lessens the agony of trial and error (Whitely, Dougherty, \& Dreher, 1991), reduces job ambiguity, enhances job performance, and decreases absenteeism and employee turnover (Lankau \& Sandura, 2002; Garvey, 1995). Mentoring has been introduced to groom high-potential recruits, especially in underrepresented groups such as women and minorities, for management positions; to promote socialization of new managers; and to fulfil their developmental needs (Hegstad \& Wentling, 2004; McCauley \& Douglas, 2004). Mentoring is critical to women as a means to break the glass ceiling in organizational hierarchies (Ragins et al., 1998; Dreher \& Ash, 1990).

Noted are marked differences between mentored and non-mentored employees. Those who have been mentored experience faster career progression; higher income; greater career commitment; more effective leadership skills; and greater career and job satisfaction (Stead, 2005; Allen, Eby, Poteet, Lentz \& Lima, 2004; Rowden, 2000; Scandura, 1992; Veale \& Wachtel, 1996; and Dreher \& Ash, 1990). They are more likely to perceive failure as a learning opportunity (Dweck \& Leggett, 1988) and take greater leap-of-faith risks (Ragins \& Cotton, 1999). Mentored employees also demonstrate greater corporate responsibility and citizenship, and interest in organizational and community volunteerism (Piercy et al., 2006; Payne \& Huffman, 2005; Chao, Walz \& Gardner ,1992). Mentoring promotes positive attitudes which contribute to reduced work-nonwork conflict, less work-related stress (Nielson et al, 2001; Higgins, 2000; Allen et al, 1997; Scandura, 1997), and lower rates of job burnout (Kleinman, Siegel \& Eckstein, 2001). Meta-analysis found mentoring to be positively correlated with promotions, expectations for advancement, and intentions to stay (Allen et al., 2004). Noted by Biech (2003), 77\% of companies with well-established mentoring programs reported enhanced employee satisfaction which translated into increased employee retention.

Mentors also benefit by experiencing increased personal satisfaction, new skills and knowledge, greater awareness of different work styles (Ragins \& Scandura, 1999), and both mentor and protégé motivation is enhanced by the psycho-social support (Scandura et al., 1996). Mentoring develops alliances to support mentors as they move strategic initiatives forward (Scandura et al., 1996); and fulfil needs for status and organizational acknowledgement in highly competitive work environments (Allen et al, 1997). 
Organizations are urged to allocate resources to leadership development - including mentoring programs - as the cornerstone of developing future leadership talent. Watson Wyatt Worldwide (2003) affirms that an organization's leadership development initiatives have a direct impact on key financial metrics, including shareholder returns, growth in market share, and return in sales; reporting 34\% of organizations that achieved superior financial results were supported by comprehensive, first-rate leadership development programs. Organizational commitment to mentorship is correlated with increased productivity and efficiency; improved management and technical skills (Rolfe-Flett, 2002); reputation for meeting or exceeding industry standards (Veale \& Wachtel, 1997); and improved employee recruitment and retention (Conklin, 2002; Baron 2000). Mentoring fosters more inclusive and collaborative work which honours diversity; encourages extensive internal and external networking; increases employee empowerment and engagement (Wanguri, 1996); and enhances systems thinking (Veale \& Wachtel, 1996). Employees are more adaptable, willing to share knowledge, better equipped to evaluate situations and make decisions (Poulsen, 2004), and acquire knowledge at a greater speed (Messmer, 1998).

\section{Challenges Associated with Attracting, Engaging, and Retaining Generation $\mathbf{Y}$}

A major challenge which faces organizations is how to attract, engage, and retain Gen Y who, because of their experiences and attitudes toward work, are markedly different from Baby Boomers in their workplace needs and expectations. Characterized as entrepreneurial and independent; digitally savvy; rejecting micromanagement; and valuing empowerment, challenge, and excitement (Izzzo, 2002), Gen Y has an unorthodox approach to career management that does not parallel traditional paths. Cited in the literature are low levels of trust and loyalty to corporate cultures, attributed to intense media scrutiny of corporations tainted with scandal (Wolburg \& Pokrywczynski, 2001) and having witnessed several instances of organizational downsizing (Loughlin \& Barling, 2001). Consequently, they have become sceptical; mistrustful, and apathetic toward traditional hierarchies and authority (Martin \& Tulgan, 2002). With Gen Y declared "the most entrepreneurial generation in history”, organizations are confronted with the added weight of convincing young workers that working for a corporation has greater appeal than self-employment (Martin, 2005).

Gen Y brings an impressive, portfolio of academic credentials and requisite skills in technology to the workplace along with lofty expectations for fast-track promotion, raises, perks, independence, flexible work arrangements, a need for fun (Zemke, 2001), and meaningful work that adds value to the organization's strategic direction (Rekar Munro, 2008). They expect continuous recognition and daily feedback (Hastings, 2008). They also call for managerial support as well as clear and comprehensive instructions, yet seek autonomy to chart the path and pace for achieving goals (Yeaton, 2008; Martin, 2005). Recent communications studies report $64 \%$ of respondents said organizational leaders lack understanding of the communication preferences of Gen Y (Reynolds, Campbell Bush, Geist, 2008). Given their pressing sense of immediacy and impatience, Gen Y is unlikely to be enticed by promises of distant pay raises and promotions (Lancaster \& Stillman, 2002). As stated by senior management interviewed by Weber (2008), "You want to think about how to prepare the next generation to move into leadership and they're already thinking about buying the company.” (p.52). 
Dissonance between personal expectations and organizational realities coupled with low tolerance of work environments that fail to deliver expectations, frequently result in swift resignation responses (Hunt \& Weintraub, 2002; Nyce \& Schieber, 2002). Job jumping every two years in search of greater compensation or purposeful work is the norm due to a boundaryless view of career and an awareness of their sought-after technological expertise (Zemke, Raines, \& Filipczak, 2000). Gen Y's definition of long term commitment is one year (Martin, 2005), and only one in five anticipates tenure with the same company for six years or longer (Hastings, 2008). Security is valued by younger workers, but is defined as career security whereby they build portfolios of transferable skills permitting them to change jobs (Lancaster \& Stillman, 2002; Hira, 2007).

\section{Steadily Increasing Labour Gap}

Further exacerbating the challenges of Gen $\mathrm{Y}$ engagement is the grave reality of a shrinking labour force. Statistics Canada (2007) reported the labour force is precariously balanced with one employee leaving for every one employee entering, yet in ten years a sharp negative replacement ratio is expected with more retirees than workforce entrants. The Conference Board of Canada (2006) forecasts an accelerated rate of retirement beginning in 2012 when $30 \%$ of older, "front end" Baby Boomers which represent 6.6 million workers reach age 65 . By 2030, a quarter of Canada's population will be 65 and ready to retire (assuming age 65 departure). By 2016, a shortage of one million workers is predicted (Barrett, 2005; McIntyre, 2007), yet more disturbing is the forecast of over ten million more jobs than people capable of filling them by 2010 (Thompson, 2003).

Instinctively, Canada looks to the United States as a source of potential labour, yet it faces the same dilemma. Approximately 60 million U.S. Baby Boomers are expected to retire in the next 15 years (Drake Beam Morin, 2003; McClintock, 2003) and 19\% of Baby Boomers in management positions are forecast to retire in the next five years (Carey, 2003). International recruitment offers little resolution as census data reports sixty-one countries are experiencing below average birth rates to meet workforce replacement needs (Kaye \& Jordan-Evans, 2005).

The arrival of Gen Y and a diminishing labour force in which to compete for talent bring new challenges and opportunities that necessitate change in how organizations attract, engage, and retain employees. Raised are the stakes for investigating Gen Y's aspirations and targeting where change is needed to become employers of choice that deliver exemplary professional development and staff HR positions with star performers.

\section{Methodology}

This research is framed within a grounded theory approach which focuses on developing defensible theories informed by events, as well as interactions of people and their communications (Halloway \& Todres, 2003). Strengths related to grounded theory include "strategies that guide the researcher step by step through an analytic process; the self-correcting nature of the data collection process; the methods inherent bent toward theory and the simultaneous turning away from a contextual description; and the emphasis on comparative methods” (Chamaz 2000: 522). 


\section{Mll Macrothink}

On-line surveys; one-on-one and focus group interviews; and video conferencing with Gen-Y HR practitioners across Canada were conducted. Participants were from small, medium, and large organizations; a variety of industries; well established and new organizations; and in private, public, and not-for-profit sectors. Data were attained from 452 participants in the formative years of their career, having one to five years full-time experience; with a higher female participation rate of $68 \%$. To ascertain mentoring needs and expectations, questions were posed in the following thematic domains:

- Framework for mentor-protégé working relationships

- Demographic profile of effective mentors

- Competency toolkit for mentoring

- Anticipated outcomes of mentoring

- Preferred approaches to learning and development

- E-mentoring

- Protégés’ contributions to mentoring relationships

- Organizational support for mentorship

TAKE IN FIGURE 1

Data analysis was conducted using content analysis, specifically the constant comparative method originally developed by Glaser (1978) and further developed by Strauss and Corbin (1990). This allowed a comparison of similarities, differences, and general patterns in responses. Each line of transcripts was reviewed to determine concepts that the data reflect. Open coding, axial coding, and selective coding (Strauss \& Corbin, 1990) allowed for progressively more complex searches for larger and more illuminating connections. Continuous reflection and synthesis of data led to emergence of themes and patterns which were clustered into categories. The goal was to keep categories mutually exclusive and to refine categories so they remained manageable and salient. Notes and personal memos were written after each interview to demarcate insights, speculations, and experiences, and to provide assistance in categorizing data.

\section{Research Findings}

Presented are aggregate results of participants' expressed needs and expectations in each thematic category.

\subsection{Framework for Mentor-Protégé Working Relationships}

When asked to rate importance of mentorship, respondents assigned a score of 8.4 out of 10, with $66 \%$ preferring to retain the same mentor for up to two years, $18 \%$ for the duration of a major project, and 9\% indefinitely. Rationale for the boundaried working relationship reflected a purpose-driven orientation. Expressed was need for a network of mentors to benefit from diverse philosophies, competencies, and insights on how HR is strategically positioned. Given the complexities of HR's mandate and its evolution as a profession, respondents perceived it improbable one mentor has the breadth of knowledge and experience to satisfy respondents' self-proclaimed appetite for learning and career progression, especially with 68\% pursuing a generalist HR pathway. Exclusive contact with one mentor would limit exposure to eclectic philosophies and practices; thus, cultivating tunnel vision in 
how they hone their signature role and contribution to HR. Minting their competitive edge as strategic contributors hinges on ability to tap into expertise from multiple sources.

Polarized responses surfaced around whether organizations should impose time restrictions on mentorship, with 52\% opposed and $48 \%$ in favour. Those opposed contended the lifespan of working relationships should exclusively be managed by mentors and protégés, with 30\% emphasizing ties should not be completely severed as proteges may need to reconnect for professional support. Signals of readiness to separate include achievement of goals (71\%); progression toward independent problem solving (58\%); and less frequent pursuit of mentor's counsel (54\%). Those in favour of pre-determined separation dates argue this compels both parties to economize resources to reach stated goals and minimizes risks of protégés becoming dependent on mentors. Also, to indefinitely commit mentors is imprudent as they may be required, or prefer, to move on to working with other new recruits.

\subsection{Demographic Profile of Effective Mentors}

When asked to declare preferred gender of mentors, male mentors were preferred by $52 \%$ of female respondents and $82 \%$ of male respondents. Females cited a need to learn from and model behaviours of males who, historically, climb corporate ladders with speed and agility. They hoped to profit from male perspectives on how women are regarded in business; canvass feedback on their business acumen, style, and approach; and gain insight on how to assert one's self on male-dominated terrain. Of the $43 \%$ of female respondents opting for female mentors, they would have more in common and engage in more purposeful conversations about values, beliefs, and challenges confronting women in business. Women in management would be models of work-life balance; and inspire them to break the glass ceiling embedded in organizational hierarchies. Male respondents cited a need to be mentored by their own gender as a matter of familiarity fostering comfort. For the $15 \%$ selecting female mentors, women were credited with being more comprehensive communicators of expectations, and providing more definitive, constructive feedback. Only 8\% refrained from declared gender preference citing mentor's competency and collaborative chemistry between mentor and protégé as more pronounced deciding factors.

Varied responses emerged when respondents were asked about preferred age of mentors. For career counsel, $74 \%$ sought older mentors who could provide accounts of personal career progression, and trial and error experiences; especially how experiences were managed and if alternative actions should have been deployed. Older mentors were also sources of insight on the evolution of HR from which to ponder its destiny. When seeking input on how to engage socially, 62\% preferred mentors of the same age who could offer advice on fitting into multigenerational workplaces. Although the majority had definitive views on age, $4 \%$ declared age irrelevant.

Academically, 27\% preferred to work with mentors who had obtained at least a Masters degree, with 56\% declaring degree status irrelevant. However, 75\% stressed the importance of professional HR designations - symbolizing knowledge, credibility, dedication to HR, and commitment to professional development. For $83 \%$ of respondents pursuing HR designations, they hoped mentors would be role models offering support and advice for attaining credentials. 


\subsection{Competency Toolkit for Mentoring}

For $84 \%$ of protégés, commitment to mentorship was contingent upon mentors' disclosure of rationale for becoming mentors - curious to uncover whether motivation was rooted in altruism and accountability for employee development, or driven by career gain and organizational politics. Also on the wish-list were insights regarding personality and work attitudes (81\%); career progression and achievements (79\%); expectations of protégés (78\%); anticipated contributions to protégé's professional maturation (71\%); chronology of mentorship experiences (67\%); and mentor's personal career map (54\%).

The crowning skills required in a mentor's competency toolkit were: leadership (66\%), effective feedback (63\%), conflict management (63\%), project management (51\%), and change management (50\%). Accompanying the skills inventory was a roster of personal attributes comprised of commitment to excellence (76\%), goal oriented (72\%), team player (61\%), resilient (58\%), and practices work-life balance (52\%).

Proteges flagged three core areas where mentors would have the most profound influence on their professional development: leadership, conflict management, and change management. Key learning points in the leadership domain included leading HR teams through strategic initiatives; developing and sustaining cohesive HR teams; and leveraging roles of leader and team player. Conflict management generated questions about polarity management - how to facilitating the process whereby differences are honoured and parties able to stay on task without splintering work relationships. In change management, inquiry zoned in on securing support and momentum for organizational change; and preventing initiatives from derailing. Also of interest was HR's role in transitioning the workforce through quantum change that rocks organizational foundations and puts deliverables at risk.

On a daily basis, protégés' expectations included: guidance in honing their competencies; career mapping; and developmental feedback. Articulated was need for mentors to encourage active experimentation, and refrain from micro-managing when protégés stumble. In lieu of being told what corrective action to take, respondents preferred to be asked probing questions to untangle problems on their own; thus, gaining confidence in their problem solving abilities. Minimized is an instinctive need to seek assistance before tapping into one's personal reservoir of solutions. In career mapping, mentors are asked to share career management strategies, especially unconventional approaches to bypass traditional pathways heavily travelled by other HR practitioners. Also of interest were approaches for managing disillusionment when faced with unchallenging work and how to persevere until the job search lands a position matching one's aspirations. In the feedback domain, preference was given to that which is constructive and formative, and invites self-critique.

\subsection{Anticipated Outcomes of Mentoring}

With regard to career aspirations, 42\% target executive roles; $26 \%$ middle management, 21\% horizontal career moves; and $11 \%$ were undecided. Of the $68 \%$ focused on upward mobility, $77 \%$ credit mentoring as integral to career progression, with $72 \%$ confident they would reach goals within six to eight years. Of $11 \%$ undecided, mentoring was identified as instrumental in helping shape career direction.

Respondents anticipate achieving the following outcomes from mentoring: 
- developing competencies en route to management accountabilities (75\%);

- professional visibility and credibility (73\%);

- high-impact networking skills (71\%);

- approaches for securing management support for business proposals (69\%);

- clarity around performance expectations, standards, and how HR achieves strategic excellence (69\%);

- $\quad$ approaches for efficient and effective project management (64\%);

- managing office politics (58\%); and,

- resolving conflicts (54\%)

Sustaining immediate and close bonds was evident, with 54\% preferring daily meetings; 22\% every other day; $13 \%$ weekly; $9 \%$ monthly; and $2 \%$ only when needed. Rewards to be reaped from the partnership include: promotion (67\%); higher income (58\%); job satisfaction (33\%); and acceptance and respect from staff (27\%).

\subsection{Preferred Approaches to Learning and Development}

When asked to characterize preferred approaches to learning, 65\% favoured hands-on, exploration compelling them to pool their own resources in the planning and execution of their work. Respondents wanted to test the fortitude of their project management skills, rationalizing how trial and error reinforces learning more potently than having a safety net of meticulously prescribed game plans handed down to shepherd them through each step. Respondents reasoned that the risk-taking ingredient pervading an exploratory approach reflects positively on their professional image, especially if mentors target them for leadership roles where risk-taking is critical in pioneering new directions. Thirty-five percent favoured planned and prescriptive approaches to projects arguing trial and error reflects poorly on competence and credibility.

As for the degree of challenge in assigned tasks, $41 \%$ preferred to be challenged within their comfort zone, and 59\% preferred to be stretched beyond. Those preferring maximum challenge were inclined to do so knowing mentors would be available to buffer falls and help with recovery and transition. Of premier importance was being assigned projects framed within the context of organizational values, vision, and mandate to grasp HR-organizational connectivity. Subsequently, their work would stand as legitimate strategic contributions from which their professional reputation would be honed. Results from previous studies reveal that according to $68 \%$, making connections to the organization's mandate early in one's HR career is fundamental in preparation for management positions (Rekar Munro, 2007).

Surprisingly, 61\% expressed interest in becoming reflective practitioners examining their philosophies, assumptions, and practices; and assessing critically their value-added contributions. Reflection on process was perceived as significant because of the high concentration of HR-employee interaction, and the cause-and-effect impact and accountability HR has on attracting, motivating, and retaining staff. Specific developmental needs include how to enable and engage self-reflection (61\%), and approaches for sustaining commitment to introspection amidst unprecedented demands on time (59\%). Reflection was noted by $55 \%$ as the cornerstone for gauging alignment of personal values and priorities to 
those espoused by the profession. For $22 \%$ this would serve as a "check-in" on their progress, with $65 \%$ wanting to move personal insights into more formalized goal setting to close gaps between what they bring to HR and expectations of the profession. Thirty-eight percent noted self-reflection would enable more precise articulation of their mentoring needs and expectations.

When asked if their workplace cultures support reflection, 29\% responded in the affirmative, $32 \%$ in the negative; and 39\% were uncertain. In workplaces that espoused self-reflection it was evident in team meetings where airtime was granted to reflection on process; in performance evaluations encouraging staff to give voice to their reflective process culminating in goal setting; and in teambuilding where process and productivity were of equal weight in the formula for success.

\subsection{E-Mentoring}

Despite their propensity for digital connectivity to the world, e-mentoring is not embraced by Gen-Y HR practitioners. Although teleconferencing and videoconferencing afford opportunities for on-line mentoring, it received a chilling approval rating of $18 \%$. Respondents forecast e-mentoring would depersonalize mentor-protégé alliances and learning, resulting in loss of motivation to continue. Given extensive interaction between HR and the workforce, learning through job shadowing was more impactful, especially when mentors manage complex or sensitive organizational issues. Respondents expressed grave concern about the degree to which e-mentoring fosters networking bonds salient to professional viability. Also queried was the depth and breadth of feedback that could be provided - much sought-after by protégés.

However, 74\% applauded electronic communication as a supplement to in-person mentoring when questions of low importance need to be addressed or when mentors were on extended offsite assignments. Fifty-four percent were in favour of e-mentoring for HR practitioners with international career aspirations. In such cases, e-mentoring offers its own brand of value in educating protégés about inter-connectedness of business operations to achieve global mandates; organizational and industry challenges on environmental, legal, social, economic, and political fronts; and how this intricate web of operations is managed. Forty-one percent would entertain a one-year contract as an HR expatriate, with $78 \%$ wanting home country and host mentors to support the journey.

Of the $18 \%$ favouring e-mentoring, they claimed it enhances communication as online correspondence requires greater precision in conveying content and tone and is more efficient since posts can be sent and answered any time without traditional challenges of making arrangements to meet and discuss issues. Noted, however, its success is contingent upon mentor's support for and comfort with technology.

\subsection{Protégés’ Contributions to Mentoring Relationships}

When asked about personal commitments to mentoring, responses included capitalizing on professional development (82\%); building rapport with mentors (75\%) and being equally contributing partners in the relationship (52\%). Respondents pledged to remain receptive to new ideas; thoughtful in considering HR practices that might clash with what they espouse; and patient with themselves as they stretch beyond their comfort zone. Some anticipated their 
learning would give rise to a paradigm shift in how they view their role as strategic HR practitioners.

Prior to starting formal working relationships, respondents want mentors to have the following information about them:

- work experience; including achievements, contributions, and performance feedback received (86\%)

- $\quad$ education and learning style preferences (81\%)

- career and academic goals so learning opportunities can be charted (79\%)

- strengths, weaknesses, and insecurities, with focus on how they are transitioning the latter into strengths (71\%)

- $\quad$ personality sketch including temperament, attitudes, and values (52\%)

- Interestingly, 9\% would refrain from disclosing personal details, concerned it could feed self-fulfilling prophecy.

A polarity emerged when asked what mentors can learn from them, with 51\% confident they can make contributions, 38\% expressing reservations, and 11\% stating they offer nothing of significance. Those expressing confidence bring technological expertise; knowledge of Gen $\mathrm{Y}$ to assist with attracting and retaining new recruits; different perspectives on HR to contribute lively conversation; best practices in HR from formal education; and, insight on what it is like to be new recruits with incessant questions and apprehensions about the work world. Of the $11 \%$ stating they offer nothing significant, mentoring was viewed as one-way learning and seasoned practitioners were unlikely to learn from those who had not yet cut their professional teeth in the field.

\subsection{Organizational Support for Mentorship}

Accountability for championing mentorship programs was assigned to various organizational stakeholders, with $29 \%$ claiming it as exclusive responsibility for an organization's executive team; 36\% assigning leadership accountability to HR; and 35\% arguing mutual accountability of both stakeholder groups. Seventy-one percent supported development of mentoring policies and procedures, with $67 \%$ recommending annual evaluations to monitor mentoring effectiveness and 62\% supporting screening and training for mentors regardless of seniority. Promisingly, 63\% stated they would be receptive to being on project teams championing implementation of mentoring programs in their companies, with $72 \%$ willing to participate in the pilot-run of such programs.

\section{Discussion}

Research findings reveal Gen Y's drive to develop competencies for senior HR accountabilities; propensity for experimentation; and quest for understanding how HR fulfils strategic mandate. Mentoring is fundamental to Gen Y's development as they make meaning of links between professional and organizational accountabilities. Specifically, mentoring communicates HR's role and contribution; how strategic relevance is woven into HR initiatives; and the complexities of fulfilling strategic mandate in an unpredictable and unsteady business landscape. Through active experimentation - under the mentor's protective umbrella of support and guidance - understanding strategic human resources management 
incrementally evolves. Immersed in HR culture, their philosophies and practices take shape as the bedrock upon which they navigate change as future leaders.

The need for mentoring programs with pre-eminent strategic orientation is timely and fundamental given lingering concerns about HR's leadership presence in propelling strategy into action with viable business returns - a concern within the profession and at the executive level (Ulrich, 2003; Ulrich, 1997). Mentoring has potential to be the catalyst for landmark change in this area, building the profession's bench strength in understanding and executing strategic imperatives. With shared understanding in the profession, practitioners approach their work grounded in the universality of planning and implementing HR initiatives with strategic relevance; and evaluating their work with strategically-sensitive metrics. Operating under this strategic microscope, positions HR as legitimate, equal partners in the executive boardroom - vigilant, accountable, and rigorously testing new initiatives for value.

To accommodate this shift, the profession needs to reframe its thinking about responsibilities at career entry. With new recruits typically assigned administrative portfolios, there is limited opportunity for putting theory acquired from academic studies into practice which ultimately, hinders ability to showcase talents and expertise. By stretching walls of accountability encouraging collaboration with experienced HR colleagues on projects with a strategic bend - the profession capitalizes on the rich competency profiles of its newest organizational members. If these projects involve interdisciplinary collaboration it may accelerate internal networking for new recruits - critical in a profession responsible for managing human resources across departmental borders - and help them comprehend how their work permeates the organization. Embarking on challenging projects early in one's career fine-tunes personal and professional resources to achieve greater success later on (McCallum, 1990).

Given the weight new HR recruits place on mentoring, undoubtedly an organization's professional development plan will be scrutinized prior to applying for employment. Companies promising to groom new recruits for strategic leadership will likely be earmarked as employers of choice. This stands as a landmark victory given recruitment challenges of the decade - the grim reality of a shrinking labour force, coupled with heightened demand for HR practitioners as organizations comprehend the value-added contributions afforded by premier management of their workforce. With demand outweighing supply of qualified HR practitioners, organizations that deliver mentoring programs aligned with Gen Y needs and expectations will win the recruitment race. Organizations able to attract the select few who will eventually champion organizational initiatives that attract, motivate, and retain an organization's workforce, will be positioned for competitive excellence in the global knowledge economy.

If companies choose not to deliver, they risk losing status as employers of choice and facing turnover when dissatisfied new recruits resign. Turnover has a crippling effect, especially on bottom line. Costs of turnover stemming from three primary sources - separation costs for departing employees; replacement costs associated with recruitment and selection; and training costs for new hires - are two to three times the monthly salary of departing employees (Mercer, 2002). Recruitment and selection costs alone for an entry level position are $\$ 6000 \mathrm{Cdn}$. (Leibowitz et al., 1991). Costs are likely higher as equations do not include 
indirect costs, such as decreased morale, lower productivity preceding resignation, and overtime payouts for employees juggling responsibilities of employees who have left.

Turnover perpetuates a cycle of recruitment, selection, and training which is expensive and robs time and attention from strategically important work that fulfils organizational mandate. With the complexion of the workplace constantly changing as a result of a steady stream of new employees, sustaining organizational stability in performance and productivity is challenged, especially critical in consumer-driven economies where consistency and excellence in service and product delivery are demanded.

Succession planning is also hard hit since it relies heavily on workplace constancy. With short-lived tenure it becomes problematic to work with employees on mapping internal career progression and providing requisite professional development, especially for leadership in key functionalities requiring extensive and intense mentoring to target competencies. Hence, the risks are high that without mentorship programs tightly linked to succession planning, organizations face a scarcity of future HR leadership talent.

That which new HR recruits experience during their formative years is what they know, and consequently model. Both enriching and rocky experiences have implications for how new recruits will perform in management positions, and how they will eventually mentor new recruits in their own HR departments. Less than exemplary, quality mentoring may be perpetuated throughout the organization, and if not salvaged, may perpetuate turnover. Conversely, a track record of excellence in grooming junior staff and a pattern of positive feedback regarding the role of mentorship in shaping future leaders are powerful marketing tools to ignite organizational interest in progress being made; convey value-added organizational impact; and recruit the next round of mentors. Although these expectations appear daunting to fulfil amidst the barrage of hurdles organizations face, investing in mentoring programs yield business implications that position organizations for operating in complex economic times.

\section{A Conceptual Model: Mapping the Route for Mentoring Generation-Y HR Practitioners}

In practice, few conceptual models of formal mentoring exist despite widespread support for their use (Kim, 2007). Presented is such a model with an unconventional twist on mentoring that sparks synergy between organizational objectives and personal values to enhance Gen Y's preparedness for strategic business partnership. This five-phase approach honours generational preferences, and supports professional and organizational excellence. Since no model for change is an airtight fit for every organization, this model should be accompanied by a level of agility so design and delivery respond to organizational fluctuations and complexities.

\section{TAKE IN FIGURE 2}

\section{Phase 1: Developing and Sustaining a Culture of Social Responsibility for Mentoring}

Organizations are called to venture beyond extolling the virtues of mentorship and to ask tough questions - what internal changes must be made to accommodate mentoring; and are we prepared to expend the resources? Although many organizations have implemented 
formal mentoring programs, most have not strategically aligned them with long-term objectives (Friday \& Friday, 2002).

Far too often in our zeal to model excellence in the competitive business arena, programs are hastily launched and quickly meet their untimely demise. Often initiatives are criticized for their inherent flaws as viable business practices when in fact, the microscope should focus on organizational infrastructures. Under the lens a disconnect between new program demands and existing organizational structures and practices are often detected. In a recent study, supervisors confessed the chilling reality that mentoring is exhaustive and intrusive on an already fast-paced and overburdened work schedule. Given a business landscape of unprecedented and unpredictable change and an HR culture characterized by chronic hours, fatiguing workloads, and shrinking deadlines, employee development typically take a backseat. Hence, noble intentions to develop mentorship are trumped by organizational constraints causing programs to lose steam and be discarded (Rekar Munro, 2007).

In the tug-of-war between advocating for mentorship and nurturing its development, what are the root cause culprits that derail its implementation and sustainability? Addressing this concern requires diving deep into the HR department and combing all functionalities to expose impediments. Unearthing the root cause beneath organizational symptoms entails comprehensive auditing of:

- departmental objectives, policies, and strategies, and how they support organizational mandate;

- policies, procedures, programs, and activities in each HR functionality;

- $\quad$ work design, practices, technology, and communication channels;

- mechanisms for employee engagement, decision making, and support;

- management-staff working relationship;

- satisfiers and dissatisfiers earmarked by the HR team; and,

- stakeholders' perceptions of efficiency and effectiveness of HR services.

Full disclosure of operations invites conversations about primary interventions to

improve operational and strategic efficiencies. Although an infinite number of interventions are plausible, the goal is to select pathways that most proactively diminish that which strangles new program implementation and sustainability - even though the best routes may be more logistically complicated and exhaustive of one's resources.

On the roster of possible interventions are job re-engineering; streamlining operations for maximum effectiveness and efficiency; forging internal and external project support and collaborations; refining communication channels; and expanding e-HR. Of paramount concern is whether full technological capabilities are being harnessed, especially in a digitally sophisticated era imprinted with lightening advances. Exercising due diligence through primary interventions alleviates operational burdens that stifle efficiency and effectiveness so 
mentoring can flourish within an infrastructure that commits resources to its formation, implementation, and longevity.

\section{Phase 2: Preparing for Mentorship}

Helping HR recruits acclimatize to and wholly embrace the organization warrants careful mentor-protege matching so experiences transcend casual knowledge exchanges and are noted for holistic value. Establishing formidable and impactful mentorship programs calls for meticulous selection and development of prospective mentors. At the starting gate a competency profile for effective mentorship is needed for identifying and inviting potential mentors to participate. Although traits of effective mentors have been well documented, they best serve as a preliminary point from which organizations craft profiles uniquely suited to their visions and values; periodically reviewed to sustain their currency and viability.

Professional development for mentors should be compulsory as mentoring relationships have a higher probability of success if mentors are trained (Stott \& Sweeney, 1999). The following blueprint for training is offered:

- adult learning principles and practices to create climates conducive to learning;

- timely and constructive feedback;

- proactive problem solving and decision making;

- progress consultation;

- conflict management and resolution;

- co-creating developmental assignments;

- support for goal setting and generating options for action strategies;

- introducing supports to "learn how to learn";

- facilitating career development discussions;

- linking protégés with internal and external networks and resources; and,

- moving protégés from dependence on mentors to interdependence on organizational networks.

Compatibility matching of mentor and protégé should be executed with the same care and precision afforded to training of mentors. Networking events and organizational collaborations are a backdrop for informal conversations from which to determine whether there is "working chemistry" as the foundation for working together. Full discretion for this decision is participant-driven so both parties are confident there is enough to bind them. Self-directed matching also empowers protégés to find mentors that represent their vision of role models.

\section{Phase 3: Mentoring in Action}

Career entry is a time when expectations collide with organizational realities, giving rise to a stinging reality shock. In phase three, mentors and protégés enter into consultation to diminish this shock through conversations about how jobs link to organizational vision and mandate; job and organizational expectations, accountabilities and opportunities; and the organizational culture and infrastructure within which to contribute. The stage is also set for mentorship mapping - exchange of needs and expectations; and co-creation of goals and 
learning outcomes for this partnership. If solid rapport is built, a safe haven exists for protégés to test their professional wings in offering feedback, suggesting change, and asking questions - even those with business sensitivity. Hence, mentors gain insights into business operations through the protege's lens.

Although initial stages of most formal mentoring are driven by extensive planning whereby protégés set goals and chart supporting action plans, there is merit in experimentation as the starting point. Protégés are often given carte blanche to articulate what they hope to gain from mentoring, yet may hesitate to do so having limited professional and organizational knowledge and experience from which to declare precise and meaningful directions. Consequently, they surrender to hazy goals that propose vacuous directions and offer even less motivational value.

Comprehensive planning is invited to take a back seat allowing a measure of uncertainty and spontaneity to live in mentoring so protégés can experience the organizational world in its raw form and explore as intuition guides them - a practice likely welcomed by Gen Y given their orientation toward experimentation. In this exploratory lab, new insights about their passions, talents, challenges, needs, and interests awaken from which they are more likely to express with conviction, fundamental needs and expectations; and formulate substantial goals to advance their careers.

Experimentation ahead of laying carefully crafted plans for action is supported by Iberra (2003) whose research on midlife career transitions advocates a test-reflect framework for defining and exploring new career interests. Quinn (1996) concurs advocating that to achieve excellence, one must break from the status quo and engage in ongoing experimentation, reflection, and evaluation. Experimentation with its inherent risk-taking is especially important in the HR profession where, as change agents, exploration is fundamental in moving organizations into uncharted territories as part of the mechanism that fuels competitive advantage.

From experimentation, needs and expectations crystallize setting the stage for protégés to create personal mission and accountability statements grounded in organizational vision and values. Expressed are roles, commitments, anticipated workplace contributions, and goals for developing full HR competency. Accompanying goals are comprehensive action plans, strategies for staying on track, and measurable outcomes expected. Emergent is a developmental plan serving as a roadmap for workplace contributions and career advancement.

Charting long term goals plants a clear and realizable vision of career possibilities that motivate protégés to excel in workplace initiatives and which feeds into organizational succession plans and Gen Y retention. If protégés remain fixed on long term vision it is likely they will ride occasional waves of monotony knowing their compass points in the direction that garners greater satisfaction.

To sustain momentum for the development plan as a working and living compass for direction, it should be the focal point in mentor-protege meetings to measure progress, strategize new directions, and articulate resources to support goal achievement. To further diffuse the probability of goal setting becoming an academic exercise, goal setting initiatives 
should take their rightful place in performance evaluations. Formal assessments ensure career aspirations are on the radar and assessed to gauge whether revisions are needed to fine-tune or excel career direction.

\section{Phase 4: Collaborative Inquiry: An Action Research Framework for Protégé and Mentor} Teams

Traditional approaches to mentoring advocate working relationships built exclusively between mentor and protégé. Given the importance of establishing mentoring programs that support organizational mandates; and the significance of workplace collaboration in achieving strategic outcomes, a wider circle of partners in mentorship is suggested. Accountability for acclimatizing protégés to the organization and moving them forward in their careers should rest with the entire workplace community allowing diverse knowledge, insights, and experiences to shape learning and development. Mentors with diverse organizational experiences are best suited to guide protégés through political arenas and workplace complexities (deJanasz \& Sullivan, 2004). Given what is known about the power of teams, especially their ability to collectively pool resources to manage transition (Hackman, 2002), mentorship should be a collaborative undertaking built on team strength. Unfolding is a community of practice ultimately, establishing a network of support that has longevity beyond formal mentorship.

\section{Protégé Collaborative Inquiry Teams:}

Founded on action research philosophy, new recruits meet for monthly debriefing sessions to discuss progress and challenges on the mentorship journey. Protege teams complement mentor-protege collaborations enabling new recruits to benefit from each other's unique perspectives and words of wisdom which are signature stamps of peer groups. Team composition can exclusively consist of HR recruits to fully explore professional development within their field, or an amalgamation of new recruits from across organizational disciplines. At the inaugural stages of career development, interdisciplinary collaboration could minimize professional silos and shape understanding of collective accountability for organizational success. Pushing the envelope, some organizations may encourage collaborations with new recruits from other facilities or partnering organizations. In doing so, new recruits experience the similarities and differences of executing the HR function across organizational cultures and infrastructures, and build professional networks.

Regardless of team configuration, dialoguing with colleagues in self-managed teams provides a forum for sharing experiences and significant learning; offering input in refining personal mission and accountability statements; formulating action plans for goal achievement; offering peer support and resources; and, seeking input on how to manage difficult situations. Colleagues - in this consulting role - pool collective wisdom to chart proactive solution strategies empowering each other with action strategies to take back to the workplace and, in subsequent months, reunite with their team to report on outcomes. The consulting role is grounded in Knowles' (1980) adult learning principles crediting peer groups - with their mutual exchange of knowledge and experiences culminating in a climate of support and encouragement - as the richest learning experience. Seyler et al. (1998) concur, stating peer support has a positive impact on transfer of learning by providing the necessary social support to move toward professional goals. 
Built into the action research framework is reflection on the process, especially personal growth and development during transition. Commitment to becoming a reflective practitioner - identified as a key developmental need in the research - enables protégés to leverage task and process dualities; and comprehend the value of reflection on professional development. Assuming protégés promise more than a cursory review of who they are and what they hope to become, reflection has potential to awaken refreshingly new insights regarding one's assumptions, business philosophy, and approach to leadership. When protégés become less protective of their personal constructs and remain curious about and receptive to change, they escape the treadmill of standard practices and mindsets that entrench them in the status quo, and unlock vast potential to be exploratory (Rekar Munro, 2005).

Reflection gains momentum and takes on a new dimension in conjunction with collaborative inquiry. In the exchange, protégés recognize the universality of their experiences which, in turn, mobilizes them to collectively conceptualize how to foster change en route to professional growth and development. Emergent is a community of practice that values and seeks excellence by leveraging reflection and action planning to fulfil personal, professional, and organizational directives.

In this cyclical action-reflection process, protégés become cognizant of their personal wealth of resources and the power of networking. As protégés capitalize on personal resources, they formulate their own repertoire of best practices and test their effectiveness in practice. This exploratory training ground is the doorway to success as the skills developed are pillars of HR success. Anticipated, when practicing in senior HR positions, protégés will facilitate action learning in their own teams as a vehicle for engaging collaborative inquiry and problem solving.

As protégés become more adept at managing action research, they begin to transition from mentor-dependent to interdependent on colleagues - collaboration recognized as the cornerstone of professional success. In a knowledge-driven economy where the speed with which one responds to change is the new measure of success, survival is contingent upon the strength of one's network which opens doors to a wealth of expertise.

\section{Mentor Collaborative Inquiry Teams}

With protégés as the focal point in mentorship, mentors' developmental needs often take a back seat even though their roles as leaders, coaches, and confidantes are fundamental to success in the mentor-protégé partnership. Mirroring the action research framework for protégé teams, mentors should have their own network of colleagues to report progress; raise questions; and canvass input on challenges faced. Armed with colleague-recommended strategies for success, mentors return to their mentoring assignments with a rejuvenated outlook and approach for managing targeted situations, agreeing to report on progress at subsequent team meetings. It is also a venue for celebrating successes and sharing best practices to be incorporated into mentoring training programs and into mentoring policy and procedures. Action research stands as a powerful vehicle for charting unconventional pathways in mentoring - through personal experiences and those of the team - to move protégés through transition. 
It is anticipated a colleague network can sustain mentoring momentum, especially during crisis points in mentor-protégé partnerships. On what could be a potentially isolating path, risks are high that mentors will hit unexpected roadblocks that rattle their confidence as mentors and certainty regarding how to proceed. If not addressed, it may negatively impact working relationships and the organization's ability to attract others to the mentoring role. With regular “check-in's” built into the action research framework, potential derailments can be repaired before causing damage.

Action research framework encourages mentors to be reflective about their mentoring philosophies, assumptions, and practices; and to pinpoint where personal change is invited. Possibly, critical reflection will extend to their HR practice inviting them to engage in deeper reflection on role and contribution. It is anticipated that mentors, in their role as HR practitioners, will not only adopt, but engage their own teams in discussion on how to integrate critical reflection into daily functionality. Long term, how can reflective practice be embraced and embedded throughout organizations so that it is viewed - alongside task focus - as equally value-added to strategic direction and fulfilment of strategic mandate.

\section{Phase 5: Evaluation}

Evaluation affords an opportune time to critique strengths and limitations of each component of mentoring - learning, development, service, coaching, and partnership. From the strengths, best practices can be extrapolated to develop the mentorship architecture; namely competency profile, training, and policies and procedures to roll out organization-wide mentorship initiatives. Best practices can also be shared with the larger organizational community to encourage dialogue and establish new benchmark standards to which organizations aspire.

Limitations are equally potent developmental opportunities from which to catch problematic areas before they derail the process, and canvass recommendations to transform weaknesses into strengths. Evaluation also ignites questions which feed new research initiatives to advance understanding and development of mentorship programs.

Recommended is an evaluative process markedly different from traditional post-implementation assessments. With evaluations administered at the conclusion, few opportunities prevail to make changes for the benefit of protégés that provided feedback. Any modifications are usually intended to enhance future mentoring; making it questionable if these changes are aligned with the needs of subsequent protégés. Hence, the evaluation should not be a conclusionary assessment, but a continuous process woven into mentor-protégé relationships. Regular “check-ins” heighten mentors' awareness of success in creating a learning environment and positions them to initiate change. It helps open communication channels so emerging issues have a forum within which to be addressed. Regularly voicing concerns decreases the probability of problems festering and potentially eroding satisfaction performance. Making changes based on protégé feedback launches a cyclical feedback process whereby mentors develop and sustain a connection with protégés disclosing that which is, and is not, contributing to learning and development (Rekar Munro, 2005). 
With organizational pressure to demonstrate return on investment, HR's compass must be fixed on delivering ROI data to justify mentoring costs and benefits and rule on organizational impact. Metrics take shape around many variables: performance measures, productivity, retention, succession planning goals, and satisfaction ratings appraised through surveys, interviews, and performance evaluation results. Articulating deliverables could also cement the business case for launching the HR mentoring model on an organization-wide scale.

Honing in on metrics sets the stage for pre and post assessments to measure if changes hypothesized from the mentoring plan are evident and the extent of their impact. Also inspired is baseline comparison of companies with and without formal HR mentoring programs to investigate the degree to which there are variances in key performance indicators, possibly attributable to mentoring.

Metrics are potent indicators of the measurable value of mentoring initiatives - justifying continued financial investment and support. As the benefits of the HR mentoring model showcased in ROI format - become apparent, the formalized mentoring program may surface as a norm in the HR profession from which best practices and benchmark standards ensue.

\section{Conclusion}

As organizations prepare for the arrival of Gen-Y HR practitioners as the next generation of strategic business partners in our $21^{\text {st }}$ century workplaces, questions bubble about their aspirations and how these can be incorporated into formalized mentorship programs. Mentorship has resurged as a leading employee development tool quintessential to the insurrection of a culture of high performance and excellence. Proposed in this paper is a mentorship model built on collaboration and an action research framework to spark synergy between organizational objectives and Gen Y's unique brand of assumptions, values, expectations, and behaviours. Communicated to HR recruits is a piercing message regarding the salience of strategic priorities; how strategic relevance is woven into HR functionalities and initiatives; and how HR practitioners understand and execute their roles and contributions to strategic mandate. It enables Gen Y to ascertain their signature role and contribution that will be the hallmark of strategic partnership. With a high premium placed on mentoring, organizations exercise due diligence in preparing the next generation under whose leadership global communities will thrive and in delivering a pre-emptive strike in the design and delivery of formal mentorship programs for the post-Gen Y wave of HR practitioners waiting at the workplace doorway.

\section{References}

Allen, T., Eby, L., Poteet, M., Lentz, L. \& Lima, L. (2004). Career benefits associated with mentoring for protégés: a meta-analysis. Journal of Applied Psychology. 89, 127-136.

Allen, T., Poteet, M., \& Burroughs, S. (1997). The mentor's perspective: A qualitative inquiry and future research agenda. Journal of Vocational Behavior. 51, 70-89.

Allen, T., Russell, J. \& Maetzke, S. (1997). Formal peer mentoring: Factors related to protégés' satisfaction and willingness to mentor others. Group and Organizational Management. 22(4), 488-507. 
Axelrod, B., Handfield-Jones, H. \& Welsh, T.A. (2001). War for talent (Part 2). McKinsey Quarterly, 2, 9-12.

Baron, T. (2000). IT talent shortage renews interest in mentoring. Information Week 24 April, 166-168.

Barrett, A. \& Beeson, J. (2002). Developing Business Leaders for 2010. R-1313-02-RR. New York: Conference Board, Inc.

Barrett, C. (2005). Performance and potential 2005-06: Trends reshaping our future. Conference Board of Canada. 1-5.

Benimadhu, P. \& Gibson, J. (2001). Leadership for Tomorrow: Playing Catch Up with Change. Conference Board of Canada. 327-01, 1-35.

Biech, E. (2003). Executive commentary on mentoring. Academy of Management Executive. 17(4), 92-94.

Chamaz, K. (2000). Grounded theory: Objectivist and constructivist methods. In N.K. Denzin \& Y.S. Lincoln (Eds.). Handbook of Qualitative Research (pp. 509-535). Thousand Oaks, Sage.

Chao, G., Walz, P. \& Gardner, P. (1992). Formal and informal mentorship. Personnel Psychology. 45(3), 619-636.

Conklin, J. (2002). The benefits of mentoring. Quality Progress. 35(11), 91.

deJanasz, S. \& Sullivan, S. (2004). Multiple mentoring in academe: Developing the professorial network. Journal of Vocational Behavior. 64(2), 263-283.

Dreher, G. \& Ash, R. (1990). A comparative study of mentoring among men and women in managerial, professional, and technological positions. Journal of Applied Psychology. 75(5), 539-546.

Dweck, C. \& Leggett, E. (1988). A social-cognitive approach to motivation and personality. Psychological Review. 95(2), 256-273.

Friday, E. \& Friday, S. (2002). Formal mentoring: Is there a strategic fit? Management Decision. 40(2), 152-157.

Garvey, B. (1995). Healthy signs for mentoring. Education + Training. 37(5), 12-19.

Glaser, B. (1978). Theoretical Sensitivity: Advances in the Methodology of Grounded Theory. Mill Valley, CA: Sociology Press.

Hackman, J. (2002). Leading Teams: Setting the Stage for Great Performances. Boston: Harvard Business School Press.

Holloway, I. \& Todres, L. (2003). The status of method: Flexibility, consistency, and coherence. Qualitative Research. 3(3), 345-357.

Hegstad, C. \& Wentling, R. (2004). The development and maintenance of exemplary formal mentoring programs in Fortune 500 companies. Human Resource Development Quarterly. 15, 421-448.

Higgins, M. (2000). The more, the merrier? Multiple developmental relationships and work satisfaction. Journal of Management Development . 19(4) 277-296. 
Ibarra, H. (2003). Working Identity: Unconventional Strategies for Reinventing Your Career. Boston: Harvard Business School Press.

Izzo, J. (2002). Values Shift: The New Work Ethic and What it Means for Business. Toronto: Prentice Hall Canada.

Kanter, R. (1999). Change is eveyone's job: Managing the extended enterprise in a globally connected world. Organizational Dynamics. 28, 6 - 24.

Kaye, B. \& Jordan-Evans, S. (2005). Love 'Em or Lose “Em. Barrett-Koehler Publishers.

Kim, S. (2997). Learning goal orientation, formal mentoring, and leadership competence in HRD. Journalof European Industrial Training. 31 (3), 181-194.

Kleinman, G., Siegel, P., \& Eckstein, C. (2001). Mentoring and learning: The case of CPA firms. Leadership and Organizational Development Journal. 22(1), 22.

Knowles, M. (1980). The Modern Practice of Adult Education. New York: Cambridge.

Lancaster, L.C \& Stillman, D. (2002). When Generations Collide: Who they are, Why they clash, and How to solve the generational puzzle at work. New York: Harper.

Lankau, M. \& Scandura, T. (2002). An investigation of personal learning in mentoring relationships: Content, antecedents, and consequences. Academy of Management Journal. 45, 779-790.

Linehan, M. \& Walsh, J. (1999). Mentoring relationships and the female managerial career. Career Development International. 4(7), 348-352.

Loughlin, C. \& Barling, J. (2001). Young workers' work values, attitudes, and behaviours. Journal of Occupational and Organizational Psychology. (74), 543-558.

Martin, C. (2005). From high maintenance to high productivity: What managers need to know about Generation Y. Industrial and Commercial Training. 37(1) 39-44.

Martin, C. \& Tulgan, B. (2002). Managing the Generation Mix. N.Y.: HRD Press.

McCauley, C. \& Douglas, C. (2004). "Developmental relationships” in McCauley, C \&

Velsor, E. (Eds), The Center for Creative Leadership Handbook of Leadership Development. San Francisco: CA: Jossey-Bass.

McIntyre, G. (2007). Rising to the challenge. Canadian Investment Guide. 12, 5-8.

Messmer, M. (1998). Mentoring: Building your company’s intellectual capital. HR Focus. 75(9), 11-12.

Nemanick, R. (2000). Comparing formal and informal mentors: Does type make a difference? Academy of Management Executive. 14(3), 136-138.

Nielson, T., Carlson, D. \& Lankau, M. (2001). The supportive mentor as a means of reducing work-family conflict. Journal of Vocational Behavior. 59(3), 364-381.

Noe, R., Greenberger, D., \& Wang, S. (2002). Mentoring: What we know and where we might go. Research in Personnel and Human Resources Management.

21, 129-173.

Nyce, S. \& Schieber, S. (2002). Decade of the employee: Workforce challenges facing developed economics of the world over the next ten years. Retrieved from http://www.watsonwyatt.com/surveys/hci. 
Payne, S. \& Huffman, A. (2005). A longitudinal examination of the influence of mentoring on organizational commitment and turnover. Academy of Management Journal. 48, 158-168.

Peterson, D. (2002). "Management development: Coaching and mentoring programs" in Kraiger (Ed.), Creating, Implementing, and Managing Effective Training and Development: State of the Art Lessons for Practice. San Francisco, CA: Jossey-Bass Publishers.

Pfeffer, J. \& Sutton, R. (2000). The Knowing-Doing Gap. Boston: Harvard Business School Press.

Piercy, N., Cravens, D., Lane, N., \& Vorhies, D. (2006). Driving organizational citizenship behaviours and salesperson in-role behaviour performance: The role of management control and perceived organizational support. Journal of the Academy of Marketing Science. 34(2), 242-262.

Poulsen, K. (2004). A new way of seeing mentoring, www.kmp-partners.com

Quinn, R. (1996). Deep Change: Discovering the Leader Within. San Fransisco, CA: Jossey-Bass Publishers.

Ragins, B. \& Cotton, J. (1999). Mentor functions and outcomes: A comparison of men and women in formal and informal mentoring relationships. Journal of Applied Psychology. 84(4), 529-550.

Ragins, B. \& Scandura, T. (1999). Burden or blessing? Expected costs and benefits of being a mentor. Journal of Organizational Behavior. 20(4), 493-510.

Ragins, B. \& Townsend, B. \& Mattis, M. (1998). Gender gap in the executive suite: CEOs and female executives report on breaking the glass ceiling. Academy of Management Executive. 28-42.

Rekar Munro, C. (2007). Work-life harmony practices of HR practitioners: Leading by example or in search of an example? HR Professional. Oct. 2007.

Rekar Munro, C. (2005). Best practices in teaching and learning: Challenging current Paradigms and redefining their role in education. College Quarterly. 8(3)

Reynolds, L., Campbell Bush, E., \& Geist, R. (2008). The Gen Y imperative. Communication World. 25(2), 19-22.

Rolfe-Flett, A. (2002). Mentoring in Australia. Frenchs Forest: Prentice-Hall.

Rosser, N. (2005). Mentoring from the top: CEO perspectives. Advances in Developing Human Resources. 7(4), 527-539.

Rowden, R. (2000). The relationship between charismatic leadership behaviours and organizational commitment. Leadership \& Organization Development Journal. 21, 30-35.

Scandura, T. (1997). Mentoring and organizational justice: An empirical investigation. Journal of Vocational Behavior. 51(1), 58-69.

Scandura, T. (1992). Mentorship and career mobility: An empirical investigation. Journal of Organizational Behaviour. 13(2), 169-174.

Scandura, T., Tejeda, M., Werther, W. \& Lankau, M. (1996). Perspectives on mentoring. Leadership and Organizational Development Journal. 17(3), 50-56.

Seyler, D., Holton, E., Bates, R., Burnett, R., \& Carvalho, M. (1998). Factors affecting motivation to transfer. International Journal of Training and Development. 


\section{2, 2-16.}

Stanek, M. (2001). Global mentoring programs: Business relationships beyond traditional borders. Journal of Workplace Learning. 13(2), 66-72.

Stead, V. (2005). Mentoring: A model for leadership development. International Journal of Training and Development. 9(3), 170-184.

Stott, T. \& Sweeney, J. (1999). More than a match. People Management. 13, 45-49.

Strauss, A. \& Corbin, J. (1990). Basics of Qualitative Research: Grounded Theory Procedures and Techniques. London, UK: Sage Publications.

Tannenbaum, S. (1997). Enhancing continuous learning: Diagnostic findings from multiple companies. Human Resource Management. 36, 437- 452.

Thompson, J. (2003). If you can measure it; you can manage it. J. Walter Thompson Specialized Communications Consulting Group. Presentation: Jan. 2003.

Ulrich, D. \& Smallwood, N. (2003). Why the Bottom Line Isn't! How to Build Value Through People and Organizations. Hoboken, N.J.: Wiley.

Ulrich, D. (1997). Human Resource Champions: The Next Agenda for Adding Value and Delivering Results. Boston: Harvard Business School Press.

Veale, D. \& Wachtel, J. (1997). Coaching and mentoring at Coca-Cola Foods. Human Resource Management International Digest. 5(3), 12-15.

Wanguri, D. (1996). Diversity, perceptions of equity, and communicative openness in the workplace. The Journal of Business Communication. 33(4), 443-457.

Watson Wyatt (2003). Leadership: The critical key to financial success. Drake Business Review 1, 21 - 25.

Weber, R. (2008). Managing Generation Y. Trailer/ Body Builders. 50-54.

Whitely, W., Dougherty, T. \& Dreher, G. (1991). Relationship of career mentoring and socioeconomic origin to managers' and professionals' early career progress. Academy of Management Journal. 34, 331-351.

Wolburg, J \& Pokrywczynski, R. (2001). A psychographic analysis of Generation Y college students. Journal of Advertising Research. (41), \#5, 33-52.

Yeaton, K. (2007). Recruiting and managing the "why” generation: Gen Y. The CPA Journal. 78(4), 68-72.

Zemke, R. (2001). Here come the millenials. Training. 38(7), 44-49.

Zemke, R., Raines, C., \& Filipczak, B. (2000). Generations at Work: Managing the clash of Veterans, Boomers, Xers, and Nexters in your workplace. Washington, DC: American Management Association. 


\section{Macrothink}

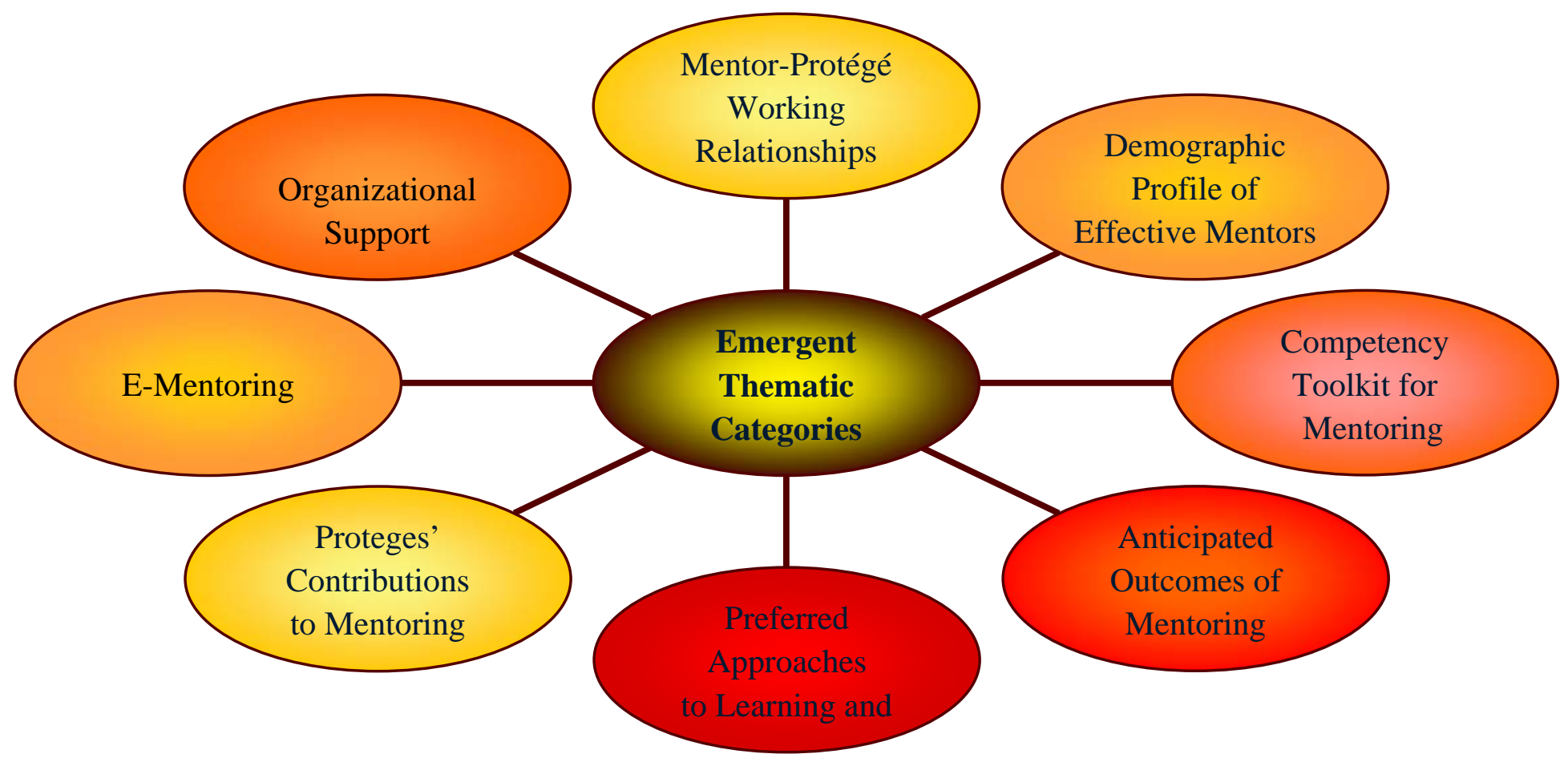

Figure 1. Research Findings: Emergent Thematic Categories

\section{A Conceptual Model: Mapping the Route for Mentoring \\ Generation-Y HR Practitioners}

Step 1: Developing and Sustaining a Culture of Social Responsibility for Mentoring

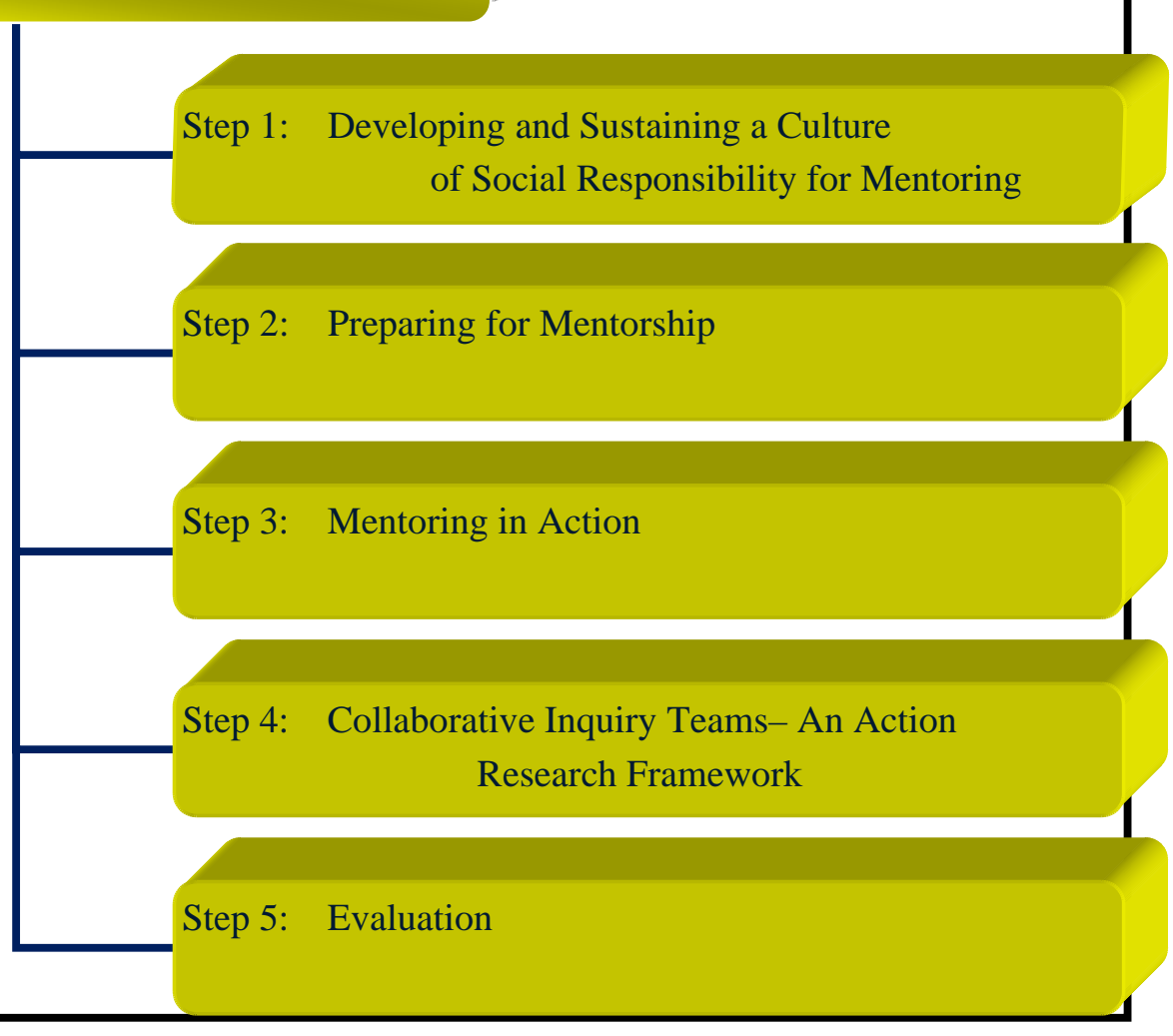

